\title{
A Progressive Neurological Syndrome Associated with an Isolated Vitamin E Deficiency
}

\author{
P. Laplante' ${ }^{1}$, M. Vanasse', J. Michaud ${ }^{2}$, G. Geoffroy ${ }^{1}$, P. Brochu ${ }^{2}$
}

\begin{abstract}
Several authors have recently reported a neurological disorder associated with chronic vitamin E deficiency in man. Except in one patient, this deficiency has always been secondary to an underlying disease resulting in lipid malabsorption. We report a second case of such a neurological syndrome in a patient in whom vitamin E deficiency was an isolated finding.

The clinical picture in our patient was characterized by a diffuse muscle weakness most prominent distally and in the lower limbs, generalized areflexia, a decrease in proprioception and vibration sense and slight limb and gait ataxia. His condition improved on alpha tocopherol therapy so that it is very likely that vitamin $E$ deficiency is responsible for his neurological deficit.

Since in our patient as well as in several other reported cases this condition has been treatable, it is important that this syndrome be recognized in children presenting a suggestive clinical picture even if they do not have lipid malabsorption.
\end{abstract}

RÉSUMÉ: Plusieurs auteurs ont décrit récemment chez l'homme un syndrome neurologique progressif associé à une déficience chronique en vitamine E. Sauf chez un enfant, cette déficience a toujours été secondaire à une maladie du système gastro-intestinal entraînant une malabsorption lipidique. Nous rapportons une deuxième observation d'un enfant présentant un déficit neurologique associé à une déficience en vitamine $\mathrm{E}$ sans malabsorption associée.

Le tableau clinique de cet enfant est caractérisé par une faiblesse musculaire diffuse prédominant distalement aux membres inférieurs, une aréflexie ostéo-tendineuse généralisée, une diminution de la sensibilité profonde ainsi qu'une légère incoordination des membres et une ataxie de la marche. Ce tableau s'est amélioré après l'administration d'alpha tocophérol, de sorte qu'il apparait plus que probable que sa condition soit secondaire à une déficience en vitamine $\mathrm{E}$.

Puisque cette maladie est traitable, il est important qu'elle soit identifiée aussi précocément que possible chez les enfants présentant un tableau clinique similaire et ce même en l'absence de malabsorption lipidique.

Can. J. Neurol. Sci. 1984; 11:561-564

In recent years, vitamin $\mathrm{E}$ deficiency has been linked with a progressive neurological disorder characterized by diffuse areflexia associated with gait and limb ataxia, impairment of sensation, muscle weakness and atrophy (Burk et al., 1981; Elias et al., 1981; Frydman et al., 1981; Grabert and Guggenheim, 1980; Guggenheim et al., 1982; Lloyd and Dubowitz, 1982; Miller et al., 1980; Muller et al., 1977; Rosenblum et al., 1981; Tomasi, 1979; Umetsu et al., 1980). Lipid malabsorption of various etiology was present in all but one patient (Burk et al., 1981). We report a second case presenting with a similar neurological deficit and in whom the vitamin E deficiency was not associated with lipid malabsorption.

\section{Case RePort}

This 10-year-old boy was the second of four children, all born from a consanguinous marriage, the parents being first cousins. Pregnancy, delivery and milestones were normal. At five years of age, he was first seen by an orthopedic surgeon for a mild scoliosis. At this time, he complained of some difficulty in walking. This problem slowly progressed over the next years and at age 10, he was admitted because of unstable gait and frequent falls. On examination, the patient was shown to be under the third percentile for height and weight. The remaining of the physical examination was normal. On neurological examination, mental functions and cranial nerves were normal. There was a mild diffuse weakness with some atrophy, both being more important distally in the lower limbs. Deep tendon reflexes (DTR) were all absent. There was also some gait ataxia and dysmetria in all four limbs. No sensory deficit was found and plantar responses were in flexion. An extensive investigation was done and the patient was discharged with the impression of a Charcot-Marie-Tooth disease.

He was readmitted 10 months later because of a rapid progression of gait ataxia and muscle weakness. He was then falling very frequently and had to use crutches to walk. He also needed help to dress and feed. On examination, there was a mild facial weakness but the rest of the cranial nerves was normal. Weakness had progressed affecting the four limbs but was again maximal distally in the lower limbs where there was

From the Service de Neurologie (1), Département de Pédiatrie and Département de Pathologie (2), Hôpital Sainte-Justine, Université de Montréal Reprint requests for complete supplement (Phase 3, Part 3) to: Prof. André Barbeau. Clinical Research Institute of Montreal, 110 Pine Avenue West. Montreal, Quebec, Canada H2W 1R7 
a severe deficit of dorsal and plantar flexion of both feet. DTR were absent. Vibration sense was decreased in all four extremities while proprioception was diminished in the lower limbs. Gait ataxia and limb dysmetria were still present but had not progressed significantly since the last admission.

\section{Laboratory Data}

Blood vitamin $E$ levels were less than $0,1 \mathrm{mg} / \mathrm{dl}$ and 0,06 $\mathrm{mg} / \mathrm{dl}$ two months later ( $\mathrm{N}: 0,5-1,2 \mathrm{mg} / \mathrm{dl}$ ). Blood smear was normal showing no acanthocytes. Beta-lipoproteins were normal. All the following tests were also within normal values: hemogram, sedimentation rate, urine analysis, blood glucose, blood urea nitrogen, electrolytes, alkaline phosphatase, liver enzymes, protein electrophoresis, bilirubin, triglycerides, cholesterol, carotene, coagulogram, serum cortisol and 24-hour urine cortisol.

\section{Radiographic Data}

A computerized tomography scan of the brain, $\mathrm{X}$-rays of the skull and lungs and barium studies of the digestive tract were normal. An abdominal scintigraphic study done with technicium after the administration of pentagastrine was also normal. X-rays of the spine showed a 15 degree thoraco-lumbar scoliosis, a spina bifida at $\mathrm{L}_{5}$ and a grade I spondylolisthesis.

\section{Electrophysiological Studies}

Motor and sensory nerve conduction velocity studies were done twice on the right median and peroneal nerves and were entirely normal on both occasions. The first electromyogram (EMG) done during his first admission was normal but on the second admission, an excess of polyphasic motor unit potentials was seen with a mild decrease in the interference pattern. Electrocardiogram, electroencephalogram and electroretinography were normal.

\section{Morphological Findings \\ Muscle}

The right tibialis anterior muscle biopsy showed mild variation in the fibre size with atrophic angulated fibres. These were

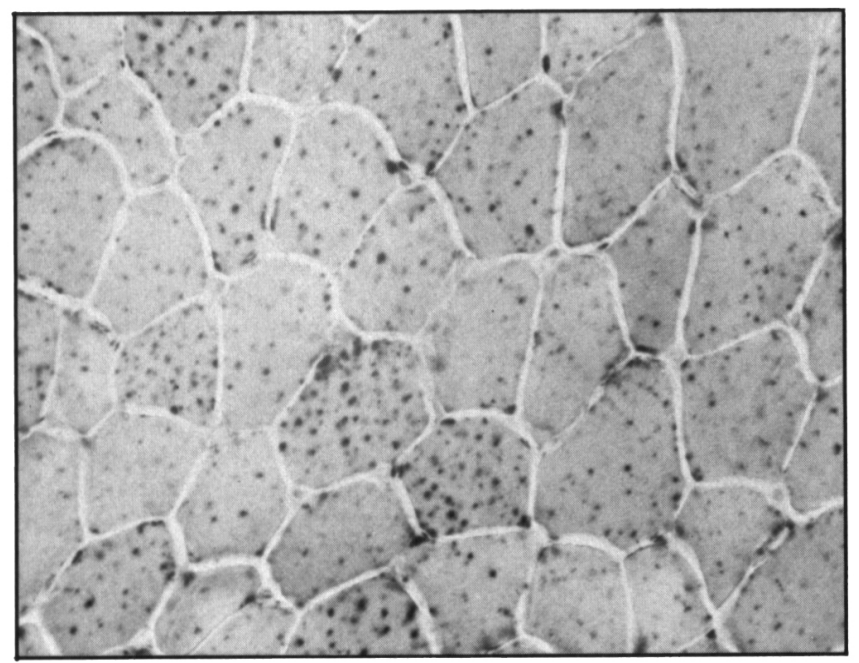

Figure I - Acid phosphatase-stained frozen section of muscle biopsy showing numerous positive flecks in the internal or subsarcolemmal portions of myofibres. $(\times 250)$ frequently found in small clusters. No hypertrophic fibres were present. The ATPase and NADH reactions showed type I fibre predominance and early type II fibre grouping. Most of the atrophic fibres reacted strongly with the NADH reactions even if most were of type II. Distributed irregularly in the biopsy, several normal or atrophic fibres contained basophilic flecks very similar to internal nuclei. However, these were positive with the periodic acid-Schiff and the acid phosphatase reactions. (Fig.l) These were also autofluorescent. Otherwise, there was no degeneration, regeneration, inflammation or fibrosis. By electron microscopy, foci of myofibril disruption were seen in several fibres. These foci were replaced by glycogen, lipid vacuoles and mitochondria. Occasionally, pseudomyelinic figures or aggregates of disorganized filaments were also seen, mostly around the nuclei. Smearing of the Z-band was also seen, rarely involving more than two or three sarcomeres. Granular membrane bound bodies corresponding to the acid phosphatase positive structures seen on frozen sections were found either under the sarcolemma or in the central portions of the fibres. They were round, ovoid or slightly irregular, isolated or in small groups.

\section{Nerves}

Plastic-embedded thick sections of the sural nerve revealed a small loss of myelinated fibres affecting all sizes. There were a few fibres with a very thin myelin layer surrounded by tiny myelin ovoids in the adjacent cytoplasm. Moderate endoneurial fibrosis was also observed. By electron microscopy, myelin debris were seen in the cytoplasm of a moderate number of schwann cells, sometimes along with evidence of remyelination. In a few axons, mitochondria, membranous dense bodies and aggregates of neurofilaments suggested axonal degeneration. Dense membrane bound bodies similar to those found in the skeletal muscle were rarely seen in the schwann cell cytoplasm of myelinated or unmyelinated fibres. The latter seemed however normal. Moderate fibrosis was noted.

\section{Evolution}

When last seen, nine months after his last admission, the patient's condition was improved and he was able to walk without crutches and dress and feed himself without help. On examination, strength had clearly improved in the upper limbs but there still was a moderately severe distal weakness in the lower limbs. DTR were absent and the deficit in proprioception and vibration sense had remained unchanged as well as the limb and gait ataxia. His serum level of vitamin $\mathrm{E}$ was normal.

\section{Discussion}

Twenty-eight patients presenting a progressive neurological disorder associated with a documented vitamin E deficiency have so far been reported (Burk et al., 1981; Elias et al., 1981; Frydman et al., 1981; Grabert and Guggenheim, 1980; Guggenheim et al., 1982; Lloyd and Dubowitz, 1982; Miller et al., 1980; Muller et al., 1977; Rosenblum et al., 1978; Rosenblum et al., 1981, Tomasi, 1979, Umetsu et al., 1980). Although some variation from case to case existed, there were striking similarities in the clinical picture as well as in the electromyographic and muscular biopsy findings in all these patients.

As can be seen in table 1, the clinical picture was characterized by a loss of deep tendon reflexes, a decrease in proprioception 
Table 1: Summary of clinical picture in vitamin $E$ deficiency patients

\begin{tabular}{|c|c|c|c|c|c|c|c|c|c|c|c|c|c|c|c|c|c|c|}
\hline & $\mathrm{N}^{*}$ & $\%$ & $\mathrm{~N}^{*}$ & $\%$ & $\mathbf{N}^{*}$ & $\%$ & $\mathrm{~N}^{*}$ & $\%$ & $\mathrm{~N}^{*}$ & $\%$ & $\mathrm{~N}^{*}$ & $\%$ & $\mathbf{N}^{*}$ & $\%$ & $\mathbf{N}^{*}$ & $\%$ & $\mathbf{N}^{*}$ & $\%$ \\
\hline $\begin{array}{l}\text { Other } \\
\text { reported } \\
\text { patients } \\
\mathrm{N}=28\end{array}$ & 28 & 100 & 22 & 85 & 10 & 38 & 19 & 65 & 19 & 65 & 17 & 55 & 14 & 48 & 12 & 41 & 18 & 28 \\
\hline
\end{tabular}

* $\mathrm{N}$ indicates the number of patients in whom this abnormal finding was present.

+ Abnormal finding present.

- Abnormal finding absent.

and vibration sense and gait and limb ataxia. Less constant features included muscle weakness, generally distal more than proximal, abnormal eye movements, retinal abnormalities and the presence of a Babinski sign. Nerve conduction velocity and/or electromyographic studies were done in 18 cases including ours (Burk et al., 1981; Elias et al., 1981; Guggenheim et al., 1982; Lloyd and Dubowitz, 1982; Miller et al., 1980; Muller et al., 1977; Rosenblum et al., 1981; Tomasi, 1979; Umetsu et al., 1980). Motor and sensory nerve conduction velocity were normal in 11 patients (including ours) and decreased in 7 (Elias et al., 1981; Guggenheim et al., 1982; Mino, 1976; Nelson et al., 1978). In four cases (including ours) signs suggestive of a neurogenic process were seen at EMG. These consisted either of abnormalities at rest (fibrillations and pseudomyotonic discharges) or excess of polyphasic motor potentials associated with a decrease in recruitment on voluntary movements. As in our patient, these signs were generally mild in contrast to the severity of muscle weakness and atrophy seen in these patients. Muscle and nerve biopsies were done in a few cases (Burk et al., 1981; Guggenheim et al., 1982; Mino, 1976; Tomasi, 1979; Umetsu et al., 1980). Muscle biopsies revealed characteristic autofluorescent, acid phosphatase positive inclusions in the myofibres. By electron microscopy, these consisted of membrane bound lipid and granular dense bodies quite characteristic of lipofuschin. Muscle biospies also showed some irregular polygonal or angular atrophic fibres with fibre grouping. Abnormalities on nerve biopsies were generally mild and consisted of loss of myelinated fibres, mostly the large ones, associated with axonal regeneration, myelin breakdown and remyelination. Our morphological findings were essentially similar except for a more patchy and uneven distribution of the acid phosphatase positive inclusions in the muscle biopsy.

There has been some speculation about the precise relationship between vitamin $E$ deficiency and the neurological deficit observed in these patients. Since most cases have been found in patients with lipid malabsorption, other metabolic disturbances could be implicated. However, observation that nearly all patients treated with oral or intramuscular supplement of vitamin $E$ have either stabilized or improved clinically (Burk et al., 1981; Elias et al., 1981; Guggenheim et al., 1982; Lloyd and Dubowitz, 1982; Miller et al., 1980; Muller et al., 1977; Tomasi, 1979; Umetsu et al., 1980) strongly support a major role of vitamin $E$ deficiency in the etiology of this neurological disorder. This is particularly true in our patient and the case reported by Burk et al. (1981) since vitamin $\mathrm{E}$ was an isolated finding. The etiology of this deficiency could not be established in either patient but an autosomal recessive hereditary defect can be suspected since both children were born from consanguinous parents.

Vitamin E deficiency has thus recently emerged as a distinct clinical problem. Since the progressive neurological disorder is treatable, it is important to recognize it as early as possible, even if malabsorption is not part of the clinical picture. Furthermore, the role of vitamin E deficiency in neuromuscular diseases will need further exploration since low serum levels of this vitamin have been reported in children affected by Werdnig-Hoffmann disease (Umetsu et al., 1980) and in patients receiving anticonvulsant drugs (Higashi et al., 1980; Mino, 1976; Ogunmekan, 1979) which can be complicated by peripheral neuropathy. (Le Quesne, 1975).

\section{ACKNOWLEDGEMENT}

The authors would like to thank Ms Françoise Benard for her assistance in the preparation of the manuscript.

\section{REFERENCES}

Burk U, Goebel HH, Kuhlendahl HD, Meier C, Goebel KM (1981) Neuromyopathy and vitamin E deficiency in man. Neuropediatrics 12: 267-278.

Elias E, Muller KPR, Scott J (1981) Association of spinocerebellar degeneration with cystic fibrosis. Lancet 2: 1319-1321.

Frydman M, Rotter JI, Kazimi-Roff P, Phelps DL (1981) Neurologic syndrome in liver disease. N Engl J Med 305, 108.

Grabert B, Guggenheim MA (1980) Neuromuscular disease related to chronic vitamin $\mathrm{E}$ deficiency. Ann Neurol 8: 217-218.

Guggenheim MA, Ringel SP, Silverman A Grabert BE (1982) Progressive neuromuscular disease in children with chronic cholestasis and vitamin E deficiency: Diagnosis and treat ment with alpha tocopherol. J Pediatr 100: 51-58

Higashi A, Tamari H, Ikeda T, Ohtani Y, Matsukura M, Miyoshino S Matsuda I (1980) Serum vitamin E concentrations in patients with severe multiple handicaps treated with anticonvulsivants. Pediatr Pharmacol 1: 129-134.

Le Quesne PM (1975) Neuropathy due to drugs. In: Dyck PJ, Thomas PK, Lambert EH (Eds.) Peripheral neuropathy, vol. 2, Philadelphia, Saunders WB, 1266-67.

Lloyd BW, Dubowitz V (1982) Progressive neurological disorderassociated with obstructive jaundice. Neuropediatrics 13: 155-157. 
Miller RG, Davis CJF, Illingworth DR, Bradley W (1980) The neuropathy of abetalipoproteinemia. Neurology 30: 1286-1291.

Mino M (1976) Long term anticonvulsivant administration and serum vitamin E. Vitamins $39,50$.

Muller DPR, Lloyd JK, Bird AC (1977) Long term management of abetalipoproteinemia. Arch Dis Child 52: 209-214.

Nelson JS, Fitch C, Fisher V, Brown GO, Chow AC (1978) Progressive neuropathologic lesions with vitamin $\mathrm{E}$ deficiency in mammals including man. J Neuropathol Exp Neurol 37: 666.

Ogunmekan AU (1979) Predicting serum vitamin E concentrations from the age of normal and anticonvulsant drug treated epileptic children using regression equations. Epilepsia 20: 295-301.
Rosenblum JL, Keating JP, Nelson JS, Prensky AL (1978) A progressive neurologic syndrome in six children with chronic liver disease and alpha tocopherol deficiency. Pediatr Res 12: 555.

Rosenblum JL, Keating JP, Prensky AL, Nelson JS (1981) A progressive neurologic syndrome in children with chronic liver disease. $\mathrm{N}$ Engl J Med 304: 503-508.

Shapira Y, Amit R, Rachmilewitz E (1981) Vitamin E deficiency in Werdnig-Hoffmann disease. Ann Neurol 10: 266-268.

Tomasi LG (1979) Reversibility of human myopathy caused by vitamin E deficiency. Neurology 29: 1182-1186.

Umetsu DT, Couture P, Winter HS, Kagan BM, Bresnan MJ, Lux SE (1980) Degenerative neurological disease in patients with acquired vitamin E deficiency. Pediatr Res 14: 512. 